Kelaniya Journal of Human Resource Management

Volume 09-Number 01-January 2014 \& Number 02-July 2014

\title{
Impact of Individualism and Collectivism on Managing Conflicts at Work: Evidence from Public Sector Banks in Sri Lanka
}

\author{
W. I. U. K. Rukshan ${ }^{1}$, H. M. Nishanthi ${ }^{2}$ \& W. G. S. Mahalekamge ${ }^{3}$ \\ 1, 2, ${ }^{3}$ Department of Human Resource Management, \\ University of Kelaniya, Sri Lanka \\ ${ }^{1}$ ukrukshan@live.com, ${ }^{2}$ menaka@kln.ac.lk, ${ }^{3}$ geethanimahalekamge@yahoo.com
}

\begin{abstract}
Conflict management is the process of planning to avoid conflict where possible and organizing to resolve conflict where it does happen, as rapidly and smoothly as possible. The ability to manage conflict is probably one of the most important social skills.

The aim of this research is to identify the influence of individualism and collectivism on managing conflicts at work place. Hence, it is necessary to identify the factors that influence on individual's conflict management styles for improving work place relations and productivity of individuals, but very few attempts have been made to find out the factors influencing managing conflicts in the Sri Lankan context. Current study employs 86 respondents who were randomly selected from the two public sector banks. The data obtained from the structured questionnaire were analysed using descriptive statistics, correlation, and regression analysis.

Through results it was found that there is a positive moderate relationship between individualism and conflict management styles. Further, it is noted that there is a positive moderate relationship between collectivism and conflict management style, and also researcher found out that out of 86 employees, $23 \%$ prefer collaborating. And also $21 \%$ of employees prefer accommodating. Two set of $20 \%$ employees prefer avoiding and compromising. The least number of employees prefer competing.
\end{abstract}

Keywords: Individualism, Collectivism, Conflict Management Style 


\section{Introduction}

Conflict is an important concept in modern management, since conflict is often inevitable whenever people work together (Brahnam, Margavio, Barrier, \& Chin, 2005). According to Rahim (2001) the term conflict refers to perceived incompatibilities resulting typically from some form of interferences or opposition.

Conflict management is the process of planning to avoid conflict where possible and organising to resolve conflict where it does happen, as rapidly and smoothly as possible (Booyens, 2008). The aim of conflict management is to enhance learning and group outcomes, including effectiveness or performance in organizational setting (Rahim, 2001).All members of any organisation need to have ways of keeping conflict to a minimum and of solving problems caused by conflict, before conflict becomes a major obstacle to the work (Yousry, Halwany, \& Shiha, 2014). On the other hand, conflict that is effectively managed can result in increased creativity, and a rethinking of goals and practices, a better informed and cohesive work group and a reformed and renewed organization (Bisno, 1988).

People differ in the management of conflict situations and conflict resolution can be obtained when both parties find common ground and work from there, and also conflict styles are patterned responses or clusters of behaviours that people use in conflict (Hocker \&Wilmot, 1995). Borisoff and Victor (1998) found that conflict handling behaviour is not a static procedure; rather it is a process that requires flexibility and constant evaluation to truly be productive and effective.

There are two basic ways of understanding the relationship between individuals in a group. The first way is individualism, which states that each individual is acting on his or her own, making their own choices, and to the extent they interact with the rest of the group, it's as individuals. Collectivism is the second way, which views it in some other way. It sees the group as the important element, and individuals are just members of the group. The group has its own values somehow different from those of the individual members. The group thinks its own thoughts. Instead of judging the group as a bunch of individuals interacting, it judges the group as a whole, and views the individuals as just members of the group (Rowlands, 2006). 
Apart from understanding different cross cultural styles as individualism and collectivism, this study address how they affects to different conflict management styles. This study is basically done in international context but not in domestically to the best of my knowledge. So the researcher has decided to bridge this research gap.

\section{Problem Statement}

Since there have been no studies done regarding this research area within the Sri Lankan context, it is expected to do the research on this topic and contribute to the current literature. Literature on this context clearly revealed that this context should be examined further. Because, no body clearly defined what is the influence of individualism and collectivism on conflict management styles. There are few researchers had conducted researches to identify the influence of individualism and collectivism on conflict management styles. But they are quite inconsistent in their findings to come a conclusion with regard this.

In spite that these studies have produced an impressive literature on the influence of individualism and collectivism on conflict management styles, there are deficiencies, and these deficiencies have impeded the further development of the research in this context. In addition, in Sri Lanka, we could not find any reported evidences in this context. These facts leads researcher to the research problem that is focused on this study is defining the influence of individualism and collectivism on managing conflicts at work by refereeing to the conflict management styles. Therefore, the research problem focussed in this study is whether the individualism and collectivism have an influence on managing conflicts at work.

\section{Objectives of the Study}

- To identify the level of individualism, collectivism in the public banking sector of Sri Lanka.

- To identify whether there is any impact of individualism on managing conflicts at work in the public banking sector of Sri Lanka.

- To identify whether there is any impact of collectivism on managing conflicts at work in the public banking sector of Sri Lanka. 


\section{Literature Review}

\subsection{Conflicts}

According to the Oxford study dictionary conflict means a fight or struggle or disagreement between people with different ideas or beliefs. According to Ahuja (1997, p. 450), conflict has been referred to broadly as the "totality of differences arising in the various value orientations of the environmental systems." According to Robbins (2003, p. 396), conflict is referred to as "a process that begins when one party perceives that another party has negatively affected or is about to negatively affect, something that the first party cares about".

Gray and Starke (1984, p. 474) viewed conflict as "a behaviour by a person or group that is purposely designed to inhibit the attainment of goals by another person or group."

Furthermore, based on the work done by Donohue \& Kolt (1992), conflict is defined "as a situation in which interdependent people express (manifest or latent) differences in satisfying their individual needs and interests and they experience interference from each other in accomplishing these goals". On the other hand, conflict is also looked at as "the interaction of interdependent people who perceives opposition of goals, aims and values and who see the other party as potentially interfering with the realization of these goals. (Che Rose, Suppiah, Uli \& Othman, 2007).

Schermerhorn, Hunt and Osborn (1997) and McShane and Ven Glinow (2005) have proposed two types of conflicts. Substantive/ Task/ Cognitive Conflict which refer to conflicts rooted in the substance of the task to be undertaken. The second type of conflict is the Affective/ People/ Emotional/ Socio emotional Conflict which refers to emotional aspects in the interpersonal relation or personality clashes or where differences are viewed as personal attacks. But Jehn (2000) categorized conflict into three types as Task conflict, Process conflict and Relationship conflicts.

It is also identified that, conflict is beginning at the individual level and ending at the organizational level. (Gary \& starke, 1984) Some scholars have explained four levels of conflict (Ahuja, 1997; Gary \& Starke, 1984). They are Intra - Individual conflict (Conflict within an individual), Inter Individual conflict (Conflict between two more individuals), Individual - 
Group conflict (Conflict between an individual and group) and Inter group conflict (Conflict between groups of people).

\subsection{Conflict Management}

Management of conflict has assumed great importance because it influences the human relations at work and also conflict management as "the use of resolution and stimulation techniques to achieve the desired level of conflict." Further Robbins (2003) explains that the conflict management is needed when the conflicting parties want to reduce it, if conflict is dysfunctional or conversely, and when it is needed to increase the conflict level, if conflict is too low (Robbins, 2003).

\subsection{Conflict Management Styles}

McSwain and Treadwell, in Hand book of practical Theology, page 194, suggest five styles as The problem solver, The super helper, The power broker, The facilitator and The fearful loser. Speed Leas, in Discover Conflict Management Styles, mentions six styles as Persuading, Compelling, Avoiding, Collaborating, Negotiating and Supporting.

Further the researcher revealed there are generally five conflict management styles of individuals. They are Competing (also called as forcing or dominating), Collaborating (also called as integrating or confrontation), Accommodating (also called as obliging), Avoiding (also called as withdrawing) and Compromising (Robbins, 2003). These conflict management styles are basically identified based on two dimensions. They are Cooperativeness (the degree to which one party attempts to satisfy the other parties concerns) and Assertiveness (the degree to which one party attempts to satisfy his/her own concerns).

Following is the description of the five conflict management styles discussed by Robbins (2003) and Whetten and Cameron (2002).

1. Competing: A desire to satisfy one's interests, regardless on the impact of the other party to the conflict. In other words, using formal authority or power that you possess to satisfy your concerns without regard to the concerns of the party that you are in conflict with. This indicates uncooperativeness and assertiveness of an individual. 
2. Collaborating: A situation in which the parties to a conflict each desire to satisfy fully the concerns of all parties. This means that cooperating with the other party to understand their concerns and expressing your own concerns in an effort to find a mutually and completely satisfactory solution. This indicates cooperativeness and assertiveness of an individual.

3. Accommodating: The willingness of one party in a conflict to place the opponent's interests above his/her own. This means that, allowing the other party to satisfy their concerns while neglecting your own. This indicates cooperativeness and unassertiveness of an individual.

4. Avoiding: The desire to withdraw from or suppress a conflict i.e. not paying attention to the conflict and not taking any action to resolve it. This indicates uncooperativeness and assertiveness of an individual.

5. Compromising: A situation in which each party to a conflict is willing to give-up something i.e. attempting to resolve a conflict by identifying a solution that is partially satisfactory to both parties, but completely satisfactory to neither. This indicates a mid-range on both cooperativeness and assertiveness. (Robbins, 2003; Whetten \& Cameron, 2002

These five are the "Pure Theories" or "Styles" for conflicting handling management. No one style is specifically used in conflict resolution. Conflict management styles differ from situation to situation. However that style might not be the style that we habitually use. (Whetten \& Cameron, 2002).

\subsection{Individualism and Collectivism}

The concept of individualism and collectivism came under discussion in 1950s. A number of researchers have analyzed the concept of individualism and collectivism in order to explain the human interactions within the organization (Gibson, 2006). According to Hofstede (1991) Individualism stands for a society in which the ties between individuals are loose, everyone is expected to look after himself or herself and his or her immediate family only. Collectivism stands for a society in which people from birth onward are integrated into strong, cohesive in-groups, which throughout people's life time continue to protect them in exchange for unquestioning loyalty. 
Individualists value their own goals, wants, needs and rights over the goals, responsibilities and obligations of the groups. They define themselves autonomous/ independent of groups. Their social behaviors are driven by their own beliefs, attitude and values. They are mostly task oriented even at the cost of relationships. Collectivists value the goals, obligations and responsibilities of the group over their own goals, wants, needs and rights. They define themselves in terms of association in various in-groups. Their social behaviors are driven by social norms, obligations and responsibilities. They emphasize on relationships, even at the cost of task completion sometime (Triandis, 1995). Hofstede (1991) presented his cultural values framework, which includes four dimensions: Individualism/ collectivism, power distance, masculinity/ femininity and uncertainty avoidance. Among these domains individualism/ collectivism is mostly used cultural value in relations to work related outcomes, processes, environment and behaviors.

\section{Conceptualization}

Based on the research question, the following conceptual model has been constructed.

Independent Variable/s

Individualism

Collectivism
Dependent Variable

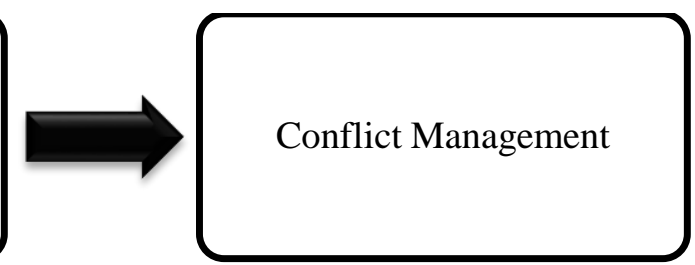

Figure 01: Conceptual Framework of the Study

\section{Hypotheses of the Study}

Based on the assumed causal influence of individualism and collectivism on conflict management styles, given in the conceptual model, the following hypotheses were developed for testing:

H1: Individualism has a significant impact on managing conflict at work

H2: Collectivism has a significant impact on managing conflict at work 


\section{Methodology}

\subsection{Population}

All Managerial and clerical level Employees of Human Resource Departments in public sector commercial banks of Peoples Bank and Bank of Ceylon considered as the population of the study.

\subsection{Sample}

Simple random sampling method has been adopted to select the employees from these banks. The bank employees were solicited to complete the questionnaire. The researcher used random sampling method as a sampling technique to select the sample. In order to select a sufficient number of elements from the population, a sample of 86 employees were used.

\subsection{Data Collection}

Data collection methods include the primary data collection methods and secondary data collection methods. Primary data gathered by using a standard questionnaire. Internet, Journal articles, Text books, Annual reports \& publications of Banks used to collect secondary data.

\section{Data Presentation and Analysis}

The collected data will be examined and analysed in a broader view by using several techniques. Here, the researcher used some statistical factors such as, mean, mode \& standard deviation, regression, person correlation coefficient analysis and SPSS version 20 and Microsoft Excel.

\subsection{Reliability of the Measures}

It is very important to the researcher to ensure the reliability of the measures which were developed to achieve a particular research purpose. Researcher tested the reliability by using Cronbach's Alpha value. Table 1 summarizes results of the reliability tests. 
Table 1: Reliability Statistics

\begin{tabular}{lll}
\hline Cronbach's Alpha & $\begin{array}{l}\text { Cronbach's Alpha Based } \\
\text { on Standardized Items }\end{array}$ & N of Items \\
\hline .833 & .827 & 39 \\
\hline
\end{tabular}

Source: Survey Data

Table 1 shows that the reliability of the variables is greater than the accepted minimum level 0.70 . If the corresponding alpha value of a given set of questions, less than 0.7 are considered to be poor. (Sekaran \& Bougie, 2010). So according to this alpha value 0.833 , it reflects reliability is high for these variables. It can be concluded that questions are reliable to measure the variable of the study.

\subsection{Descriptive Statistics}

Table 2: Frequencies

\begin{tabular}{|c|c|c|c|c|}
\hline & & $\begin{array}{l}\text { Independent } \\
\text { Individualism }\end{array}$ & $\begin{array}{l}\text { Independent } \\
\text { Collectivism }\end{array}$ & $\begin{array}{c}\text { Dependent } \\
\text { conflict } \\
\text { Management }\end{array}$ \\
\hline \multirow{2}{*}{$\mathrm{N}$} & Valid & 86 & 86 & 86 \\
\hline & Missing & 0 & 0 & 0 \\
\hline \multicolumn{2}{|c|}{ Mean } & 3.9000 & 3.8767 & 3.5389 \\
\hline \multicolumn{2}{|c|}{ Median } & 4.0000 & 4.0000 & 3.4828 \\
\hline \multicolumn{2}{|c|}{ Mode } & 3.60 & 4.00 & $3.24 \mathrm{a}$ \\
\hline \multicolumn{2}{|c|}{ Std. Deviation } & .25622 & .16851 & .40179 \\
\hline
\end{tabular}

The mean value of individualism is 3.90 and collectivism mean value is 3.87 . Both the mean values show that individualism and collectivism both high. The dependent variable conflict management styles mean value is 3.53. Mode values are 3.60, 4.00 and 3.24 for individualism, collectivism and conflict management respectively. 


\subsection{Pearson's Correlation Coefficient}

The Pearson's correlation coefficient analysis is used to measure the correlation among dependent and independent variables. Here it has run a correlation analysis to determine the correlation between individualismcollectivism and Conflict management. Table 3 and table 4 shows the output of Pearson correlation.

Table 3: Correlations

\begin{tabular}{llrr}
\hline & & $\begin{array}{l}\text { Independent } \\
\text { Individualism }\end{array}$ & $\begin{array}{l}\text { Dependent } \\
\text { conflict } \\
\text { management }\end{array}$ \\
\hline $\begin{array}{l}\text { Independent } \\
\text { Individualism }\end{array}$ & Pearson Correlation & 1 & $.348^{* *}$ \\
& Sig. (2-tailed) & & .001 \\
& $\mathrm{~N}$ & 86 & 86 \\
$\begin{array}{l}\text { Dependent conflict } \\
\text { management }\end{array}$ & Pearson Correlation & $.348^{* *}$ & 1 \\
& Sig. (2-tailed) & & \\
& $\mathrm{N}$ & .001 & 86 \\
\hline
\end{tabular}

**. Correlation is significant at the 0.01 level (2-tailed)

According to the statistics presented in Table 3, it could be said that, there is a positive moderate relationship between individualism and conflict management at a significant level of 0.01 . 
Table 4: Pearson's Correlation

\begin{tabular}{llrr}
\hline & & \multicolumn{1}{c}{$\begin{array}{c}\text { Dependent } \\
\text { conflict } \\
\text { Management }\end{array}$} & $\begin{array}{r}\text { Independent } \\
\text { Collectivism }\end{array}$ \\
\hline $\begin{array}{l}\text { Dependent conflict } \\
\text { management }\end{array}$ & Pearson Correlation & 1 & $.280^{* *}$ \\
& Sig. (2-tailed) & & .009 \\
& $\mathrm{~N}$ & 86 & 86 \\
Independent & Pearson Correlation & $.280^{* *}$ & 1 \\
Collectivism & Sig. (2-tailed) & .009 & \\
& $\mathrm{~N}$ & 86 & 86 \\
\hline **. Correlation & & & \\
& & & \\
\end{tabular}

According to Table 4, it could be said that, there is a positive weak relationship between collectivism and conflict management styles. at a significant level of 0.01 .

\subsection{Regression Analysis}

The linear regression analysis was carried out find out the impact to the dependent variable (Conflict management) with the independent variable (Individualism-Collectivism). Further if coefficient is significant at $\alpha=0.05$ in the regression analysis at $95 \%$ level of significance. It is considered that certain independent variable is important in explaining the dependable variable.

According to the summary statistics, it could be noted that, $\mathrm{R}$ square takes 0.121 value which reflects a positive impact. So the $\mathrm{H} 1$ is accepted. Therefore there is positive impact of individualism on conflict management. 
Table 5: Regression Analysis (1)

\begin{tabular}{lcccccccccc}
\hline Model & $\mathrm{R}$ & $\begin{array}{c}\mathrm{R} \\
\text { Square }\end{array}$ & $\begin{array}{c}\text { Adjusted } \\
\mathrm{R} \text { Square }\end{array}$ & $\begin{array}{c}\text { Std. } \\
\text { Error of } \\
\text { the } \\
\text { Estimate }\end{array}$ & $\begin{array}{c}\mathrm{R} \\
\text { Square } \\
\text { Change }\end{array}$ & $\begin{array}{c}\text { Change Statistics } \\
\text { Change }\end{array}$ & df1 & df2 & $\begin{array}{c}\text { Sig. F } \\
\text { Change }\end{array}$ \\
\hline & & & & & & & & & & \\
1 & .348 & .121 & .110 & .37897 & .121 & 11.542 & 1 & 84 & .001
\end{tabular}

Notes: (1) Predictors: (Constant), Individualism; (2) Dependent Variable: Conflict Management

Table 6: Regression Analysis (2)

\begin{tabular}{|c|c|c|c|c|c|c|c|c|c|}
\hline \multirow[t]{2}{*}{ Model } & \multirow[t]{2}{*}{$\mathrm{R}$} & \multirow{2}{*}{$\begin{array}{c}\mathrm{R} \\
\text { Square }\end{array}$} & \multirow{2}{*}{$\begin{array}{c}\text { Adjusted } \\
\text { R } \\
\text { Square }\end{array}$} & \multirow{2}{*}{$\begin{array}{c}\text { Std. } \\
\text { Error of } \\
\text { the } \\
\text { Estimate }\end{array}$} & \multicolumn{5}{|c|}{ Change Statistics } \\
\hline & & & & & $\begin{array}{l}\text { R Square } \\
\text { Change }\end{array}$ & $\begin{array}{c}\mathrm{F} \\
\text { Change }\end{array}$ & $\mathrm{df1}$ & $\overline{\mathrm{df} 2}$ & $\begin{array}{c}\text { Sig. F } \\
\text { Change }\end{array}$ \\
\hline 1 & .280 & .078 & .067 & .38806 & .078 & 7.122 & 1 & 84 & .009 \\
\hline
\end{tabular}

Notes: (1) Predictors: (Constant), Collectivism; (2) Dependent Variable: Conflict

Management

There is a positive impact of collectivism on conflict management according to above table. Hypothesis two of the research is" There is positive impact of collectivism on conflict management". The adjusted $\mathrm{r}$ square takes 0.067 value which reflects a positive impact. So the $\mathrm{H} 2$ is accepted.

In relation to the analysis conducted on conflict management styles, following findings were generated.

Out of 86 employees, $23 \%$ prefer collaborating. And also $21 \%$ of employees prefer accommodating. Two set of $20 \%$ employees prefer avoiding and compromising. The least number of employees prefer competing. 


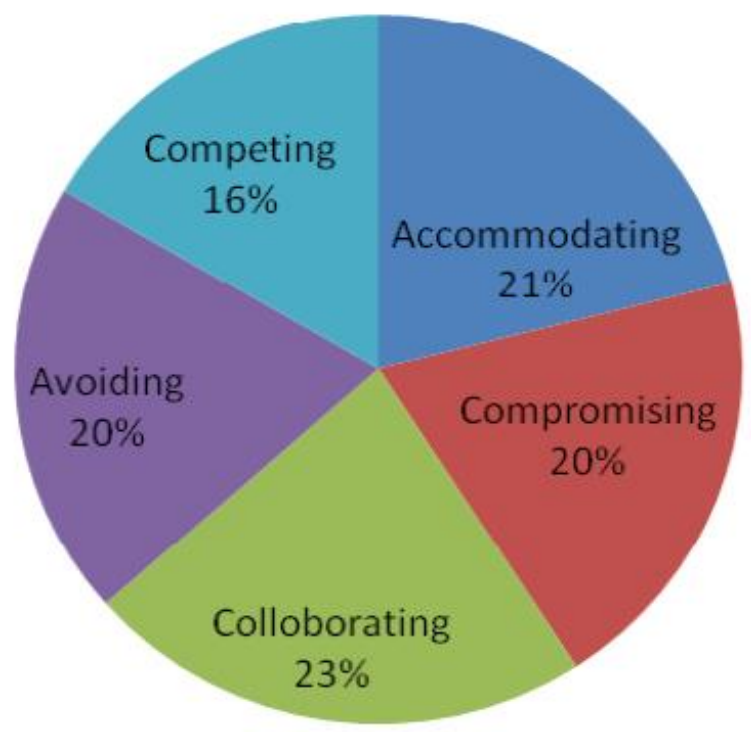

\section{Figure 3: Overall Preference of conflict management styles}

\section{Conclusion}

The current study focussed on identifying how individualism and collectivism impact to conflict management at work. This study attempts to establish a relationship of individualism collectivism with managing conflicts at work. The conflict management styles that has been focused on conflict management are accommodating, avoiding, competing, collaborating and compromising. There is a positive moderate relationship between individualism and conflict management at individual level with the major theme that this specific cultural dimension differs person to person within a culture and so the conflict management. Hence a model is proposed to elaborate this relationship. But the model isn't tested empirically. This is the major limitation of this study. Future researchers can study this relationship with empirical evidences from within a culture and across the cultures to support that, individualism and collectivism is present in each culture irrespective of the aggregate presumed nature of the culture and so individuals differs in their conflict management styles based on their personal orientation. 
Findings of the research suggest that there is a positive moderate relationship between individualism and conflict management. And also there is a positive moderate relationship between collectivism and conflict management. So the hypotheses of research were proven by the result of the study.

\section{Recommendations}

Based on the research findings and previous empirical evidences, the researcher wish to provide the followings suggestions and recommendations. People differ in the management of conflict situations. It is important to realize that no style is wrong, but that appropriate situations exist depending on the objective. (Technicomp, 1995) Through conflict self-awareness, employees can more effectively manage their conflicts and therefore their professional and personal relationships.

When employees find themselves in conflict over very important issues, they should normally try to Collaborate with the other party. This style often takes more energy, patience and time than other styles, but produces the most satisfaction. This style is particularly helpful when the issue is important to both parties, the relationship is valued, commitment by the other party is valued and different perspectives need to be merged. This style may be disadvantage, if individuals use it exclusively and disapprove of other conflict individuals not using it.

If time is precious and if employees have enough power to impose their will, competing style is more appropriate. Because of using this style, individuals may be described as aggressive, overwhelming, intimidating and over powering. Appropriate uses of the competing style are when the outcome is more important than the relationship. This may occur when quick, decisive action is vital and unpopular course of action is necessary. This style may only effective when you are right and have power. Caution exists with this style as a reputation for bullying may develop if it is used too often.

When dealing with moderately important issues, Compromising can often lead to quick solutions. However, compromise does not completely satisfy either party and does not foster innovation the way that taking the time to collaborate can. This style is most effective when the issue and relationship are both only moderately important, there is plenty of time, a temporary 
solution is sought, both sides have equal power and as a back-up mode when collaboration or competition fails.

When employees find themselves in conflict over a fairly unimportant issue, using an accommodating strategy is a quick way to resolve the conflict without straining their relationship with the other party. Further, according to McMahon (1994), this conflict management style is a smoothing gesture where the relationship is considered much greater than an individual's own goals. Employees who consistently use this style emphasises the areas of agreement while downplaying areas of disagreement. Appropriate uses of this style in situations where the issue is not as important as the relationships, feels that reserving harmony is important, realizes that subordinates need to experiment and learn from their own mistakes and one party needs special consideration.

Avoiding should normally be reserved for situations where there is a clear advantage to waiting to resolve the conflict. Generally, employees engaged in conflict with a superior most likely to respond in avoidance behaviour. The appropriate uses of the avoiding style include the situation being considered as a negligible issue, damage is pending, accessible resources are inadequate and one's objectives are not appropriate or legitimate. Moreover, avoiding is appropriate if you are too busy with more important concerns and if your relationship with the other party is unimportant.

\section{References}

Ahuja, K. (1997). Management and Organization. India: CBS publishers.

Bisno, H. (1988). Managing Conflict. Beverly Hills, CA: Sage publication.

Booyens, S. W. (2008). Conflicts. In Introduction to Health Services Management (p. 192). South africa: Juta \& Company Ltd.

Borrisoff, D., \& Victor, D. A. (1998). A communication Skills Approach. In Conflict Management (2nd ed.). Boston: Allyn and Bacon.

Brahnam, S. D., Margavio, T. M., Barrier, M. A., \& Chin, J. M. (2005). A bender-based catogarization for conflict resolution. Journal of management development, 24(3), 197-208. 
Che Rose, R., Suppiah, W., Uli, J., \& Othman, J. (2007). A Face Concern Approach to Conflict Management - A Malaysian Perspective. Journal of Social Sciences, 2(4), 121-126.

Donohue, W. A., \& Kolt, R. (1992). Managing Interpersonal Conflict. Newbury Park, California: Sage Publication.

Gibson, C. (2006). A review of empirical research incorporating. Journal of International Business.

Gray, J. L., \& Starke, F. A. (1984). Oraganizational Bahavior (3rd ed.). longman Higher Education.

Hocker, J., \& Wilmot, W. (1991). Interpersonal Conflict. Dubuque: C. Brown.

Hofstede, G. (1991). Culture and Organizations. London: McGrawHill.

Jehn, K. (2000). Enhancing Effectiveness:An Investigation of advantages and disadvantages of value based intergroup conflict. International Journal of Conflict Management, 5, 223-238.

McMahon. (1994). Leadership and conflict resolution.

Mcshane, S. L., \& Von Glinow, M. A. (2005). Organizational Behavior. McGrow-Hill Higher Education.

McSwain, \& Treadwell. (n.d.). Handbook of Practical Technology.

Rahim, M. (2001). A measure of styles of handling interpersonal conflict. Academy of Management Journal.

Robbins, S. (. (2003). Organisational behaviour (10 ed.). San Diego: Prentice Hall.

Rowlands, J. (2006). Lectures. Retrieved Aug 01, 2016, from objectivism101.com:

http://objectivism101.com/Lectures/Lecture39.shtml

Schermerhorn, J. R., Hunt, J. G., \& Osborn, R. N. (1997). Organizational Behavior (6th ed.). New York: John Wiley \& Sons, Inc.

Sekaran, U. (2006). Research methods for Business. United States of America: John Wiley \& Sons. 
Kelaniya Journal of Human Resource Management

Volume 09-Number 01-January 2014 \& Number 02-July 2014

Technicomp. (1995). Conflict management for teams. Cleveland, OH:

Author.

Triandis, H. (1995). Individualism \& collectivism. San Francisco:

Westview.

Whetten, D., \& Cameron, K. (2002). Developing Management Skills. Upper Saddle River: Prentice hall.

Yousry, M. M., Halwany, A. A., \& Shiha, E. M. (2014). Conflict management and preffered style for resolving conflict. Journal of Engineering and Computer Science, Vol 15 (No 2). 